\title{
Entomological Indicators of Malaria Transmission Prior to a Cluster Randomised Controlled Trial of a "Lethal House Lure" Intervention in Central Côte D'Ivoire
}

\section{Rosine Zlanneu Wolie ( $\nabla$ wolierosine@yahoo.fr)}

Université Félix Houphouët-Boigny Unité de Formation et de Recherche en biosciences https://orcid.org/0000-0002-3499-3114

\section{Alphonsine A. Koffi}

Institut National de Santé Publique: Institut National de Sante Publique

\section{Lesley Ayuk-Taylor}

Washington State Department of Health

\section{Ludovic P. Ahoua Alou}

Institut National de Santé Publique: Institut National de Sante Publique

\section{Eleanore D. Sternberg}

Liverpool School of Tropical Medicine

\section{N'Nan Oulo Alla Yvonne}

Université Félix Houphouët-Boigny: Universite Felix Houphouet-Boigny

\section{Yao N’Guessan}

Institut National de Santé Publique: Institut National de Sante Publique

\section{Amal Dahounto}

Institut National de Santé Publique: Institut National de Sante Publique

\section{Welbeck A. Oumbouke}

Institut National de Santé Publique: Institut National de Sante Publique

Innocent Z. Tia

Institut National de Santé Publique: Institut National de Sante Publique

\section{Simon-Pierre A. Nguetta}

Université Félix Houphouët-Boigny: Universite Felix Houphouet-Boigny Jackie Cook

London School of Hygiene \& Tropical Medicine

Matthew B. Thomas

New York University

\section{Raphael N'Guessan}

London School of Hygiene \& Tropical Medicine 


\section{Research Article}

Keywords: Malaria Transmission, Anopheles, Plasmodium, Insecticide resistance genes, Côte d'Ivoire. Posted Date: December 21st, 2021

DOI: https://doi.org/10.21203/rs.3.rs-1146656/v1

License: (c) (i) This work is licensed under a Creative Commons Attribution 4.0 International License. Read Full License 


\section{Abstract}

Background: A study was conducted prior to implementing a cluster randomised controlled trial (CRT) of a lethal house lure strategy in central Côte d'Ivoire and aimed to provide baseline information on malaria vectors in 40 village clusters.

Methods: Human landing catches (HLC) was performed between November-December 2016, capturing mosquitoes indoor and outdoor between 18.00-08.00. Mosquitoes were processed for entomological indicators of malaria transmission (human biting rates, parity rates, sporozoite infection rates and the entomological inoculation rates (EIR)). Species composition and allelic frequencies of $K d r-w$ and $A c e-7^{R}$ mutations were also investigated within the Anopheles gambiae complex.

Results: Overall, 15,632 mosquitoes were captured. Anopheles gambiae s.I. and Anopheles funestus were the two malaria vectors found during the survey period, with predominance for Anopheles gambiae s.l. (66.2\%) compared to Anopheles funestus (10.3\%). The mean biting rate for An. gambiae s.l. was almost 5 times higher than that for An. funestus s.l.(19.8 bites per person per night for An. gambiae s. I. vs 4.3 bites per person per night for An. funestus s. I.) and this was evident indoor and outdoor. An. funestus was more competent to transmit malaria parasites in the study area, despite relatively lower number tested for sporozoite index (1.6\% (1,373) for An. gambiaevs 4.7 \% (722) for An. funestus s.I.).

There was no significant difference between the proportion infected outdoor and indoor for An. gambiae s.I. (1.6\% vs 1.5\%; OR=1.11[0.65-1.9]; $\mathrm{P}=0.676)$, but for An. funestus, more mosquitoes were infected outdoor (6.4\%) than indoor (3.5\%) ( $\mathrm{OR}=1.86$ [1.07-3.23]; $\mathrm{P}=0.0249)$. The majority of both infected vectors with malaria parasites harboured P. falciparum (90.6\% for An. gambiaes. I. and 97, 8\% for An. funestus s. I.). The EIR for both vectors ( 0.43 infected bites per night) were similar and there were no significant differences for transmission occurring outdoor and indoor for both species. Of the An. gambiae s.l. analysed, only An. gambiae (14.1\%) and An. coluzzii (85.9\%) were found. The allelic frequencies of $K d r$ and $A c e-1^{R}$ were higher in An. gambiae (0.97 for Kdrand 0.19 for $\left.A c e-1^{R}\right)$ than in An. coluzzii ( 0.86 for $K d r$ and 0.10 for $\left.A c e-1^{R}\right)(P<0.001)$.

Conclusion: Despite universal coverage of long-lasting insecticidal nets (LLINs) in the area, there was an abundance of malaria vectors in the study in area in central Côte d'Ivoire, specifically highly resistant $A n$. gambiae s.l. as well as An. funestus s.l.. The malaria sporozoite rate was higher in An. funestus s.I than An. gambiae s.l.. but EIR rates in these two species were similarly high, both indoor and outdoor. Novel tools or strategies are urgently needed to further reduce malaria transmission in this area.

\section{Background}

Malaria is caused by protozoan parasites belonging to the Plasmodium genus which are transmitted by the female Anopheles mosquito during blood feeding. Over the last 10 years, considerable efforts have been made to control malaria in many parts of the world, especially in Sub-Saharan Africa. This has led to the decline in malaria transmission in many parts of Africa[1, 2]. According to the last world health 
organization (WHO) malaria report[3], the significant progress in malaria control can be attributed to a scale-up of vector control interventions, as well as improved diagnostic testing, rapid and efficient treatment of malaria patients. However, despite these considerable efforts to reduce transmission, malaria remains one of the major causes of morbidity and mortality in sub Saharan Africa[1,3]. Vector control relies on a handful of insecticides used for indoor residual spraying (IRS) and treatment of longlasting insecticidal nets (LLINs) and insecticide resistance has been widely detected in malaria vectors across the continent[4-7]. The situation is particularly worrying with an increase in intensity and mechanisms of insecticide resistance detected over time $[7,8]$. Therefore there is a pressing need for effective, sustainable tools or strategies for malaria control.

The observation that host-seeking African malaria vectors predominantly enter human dwellings through open eaves motivated the development of the EaveTubes technology[9]. EaveTubes arean innovative delivery system where insecticide-treated inserts are placed in tubes installed in the eaves of houses. These inserts enable the transfer of a high dose of insecticide capable of killing even strongly insecticideresistant Anopheles mosquitoes [10]. EaveTubes in combination with screening of windows and doors were found to reduce malaria transmission in a cluster randomized controlled trial (CRT) conducted in central Cote d'Ivoire between 2016 - 2019[11].

Baseline data on entomological parameters, including vector densities, malaria sporozoite rates, and insecticide resistant phenotypes, are valuable for interpreting the impact of an intervention like EaveTubes plus screening.

To collect these data, the current study was conducted prior to start of the CRT between NovemberDecember 2016 (the beginning of the dry season), across all study villages selected for the CRT in central Côte d'Ivoire..

\section{Methods}

\section{Study Site}

The study area has previously been described [12]. Briefly, it is an area of year around malaria transmission, with a major rainy season from April to July, a minor rainy season from August to November, and a dry season from December to March. Malaria transmission peaks after the minor rainy season in November[11].

For the CRT, forty village (clusters) were identified within a 60 kilometres radius around the city of Bouaké. The villages were selected to have $100-600$ houses, of which at least $80 \%$ were suitable for installation of EaveTubes, and all of the villages were at least $2 \mathrm{~km}$ apart from each other.

\section{Mosquito Collection}


A cross-sectional survey was conducted using human landing catches (HLC). Captures were done in each village over two consecutive nights, both indoor and outdoor, in five randomly selected households. For each capture point, one volunteer collected mosquitoes from 18:00 to 00:00 and a second volunteer took over from 00:00 to 08:00. Volunteers rotated from site to site to account for any possible differences in individual attractiveness to mosquitoes. The mosquitoes collected were kept in cool boxes and transported to the laboratory for processing the next morning.

\section{Identification And Processing Of Mosquitoes}

Mosquitoes were first identified using a morphological identification key[13]. Malaria vector species were then kept for additional processing. Due to the large numbers of An. gambiae s.l. and An. funestus s.l. captured during the HLC, only a subset of samples was analysed further.

For this subset, two to four female mosquitoes were randomly selected per collection site and their ovaries were dissected to determine parity status [14]. Of the parous female mosquitoes, up to 60 per village were randomly selected to be processed for sporozoite infection by quantitative polymerase chain reaction (qPCR) assay[15]. Up to 30 of these parous female mosquitoes were also tested for molecular identification of species[16] and to detect the Knockdown resistance gene L1014F $(K d r-w)$ [17] and the acetylcholinesterase gene G119S $\left(\right.$ Ace- $\left.{ }^{R}\right)$ mutations[18].

\section{Data analysis}

Indoor and outdoor human biting rates (HBR) measured were the mean number of vector bites received per person per night of collection $(b / p / n)$. Parity rate was the proportion of parous mosquitoes over the total dissected. The Plasmodium sporozoite infection rate (SIR) in each vector species population was the number of mosquitoes infected with sporozoites, divided by the total number of mosquitoes tested. The nightly entomological inoculation rate (EIR) is the number of infectious bites per person per night. It is conventionally the product of the daily HBR and the SIR from the caught mosquitoes. For this study, nightly EIR was calculated using the following formula:

$E I R=H B R * S I R(1)$

$E I R=\left[\left(\frac{\text { Totalvectorcaught }}{\text { Totalcapturenight }}\right) *\left(\frac{\text { Totalsporozoitepositive }}{(\text { Totaltested }+ \text { totalnon-parous })}\right)\right]$

In (2), the first term is $H B R$ and the second is $S I R$. This approach was used because the SIR was estimated assuming that all non-parous mosquitoes were sporozoite negative.

HBR, parity, SIR, and EIR for indoor and outdoor catches were analysed using generalized linear mixed models (GLMMs) with binomial distribution for SIR and parity rates, and normal distribution using linear mixed model (Imer) for HBR and EIR, in R (version 3.6.3). Capture location was included in the model as 
fixed effect and village as random effect. The sporozoite infection rate of identified local malaria vectors were compared using Pearson's chi-square test. The allelic frequencies of the two resistance genes ( $K d r$ L1014F and Ace- $1^{R}$ G119S) in An. gambiae s.l. sibling species were tested to Hardy-Weinberg equilibrium (HWE) conformity using the exact HW test and also compared.

\section{Ethics Clearance}

This study followed the ethics principles recommended by the Côte d'Ivoire Ministry of Health ethics committee (ref: 039/MSLS/CNER-dkn), the Pennsylvania State University's Human Research Protection Program under the Office for Research Protections (ref. : STUDY00003899 and STUDY00004815), and the London School of Hygiene and Tropical Medicine ethical review board (No. 11223).

Verbal and written informed consent from all participants were obtained in the local language prior to their enrolment in the study. Volunteer mosquito collectors were well trained on how to collect mosquitoes without being bitten. They received vaccination against yellow fever and the project offered treatment of confirmed malaria cases free of charge, according to the national malaria control programme policy.

\section{Results}

\section{Mosquito species composition, density and human biting pattern}

A total of 15,632 female mosquitoes were captured using HLC, of which $66.2 \%(10,350)$ were An. gambiae s.l. and 1,615 (10.3\%) were An. funestus s.l. (Table 1 and Fig. 1a). These two species were the only vectors of human malaria captured in the area. Both malaria vectors showed early biting activity (from 19.00 onward) to reach a peak around 02.00 (An. gambiae s.I.) or 03:00 (An. funestus s.I.) (Fig. 2). Biting then decreased steadily, and by dawn (06:00) it fell below $0.2 \mathrm{~b} / \mathrm{p} / \mathrm{n}$. The mean biting rate for $A n$. gambiae s.I. $(19.8 \mathrm{~b} / \mathrm{p} / \mathrm{n})$ was almost 5 times higher than that for An. funestus s.l. $(4.3 \mathrm{~b} / \mathrm{p} / \mathrm{n})$ and this was evident both indoor and outdoor (Table 2). Overall, the biting patterns indoor and outdoor were similar for gambiae s.l, however indoor biting was significantly higher than outdoor for An. funestus s.l.. $(P=0.0088)$ (Supplementary Materials). 
Table 1

Number of mosquitoes collected by human landing catch (HLC)

\begin{tabular}{|llll|}
\hline Mosquito species & $\begin{array}{l}\text { Number of females collected } \\
(\%)\end{array}$ & \multicolumn{2}{l|}{ Collection location } \\
\cline { 3 - 4 } & & $\begin{array}{l}\text { Number indoor } \\
(\%)\end{array}$ & $\begin{array}{l}\text { Number outdoor } \\
(\%)\end{array}$ \\
\hline An. gambiaes.l. & $10,350(66.2)$ & $5,714(55.2)$ & $4,636(44.8)$ \\
\hline An. funestus s.l. & $1,615(10.3)$ & $1,034(64.0)$ & $581(36.0)$ \\
\hline $\begin{array}{l}\text { Other Anopheles } \\
\text { spp }\end{array}$ & $894(5.7)$ & $428(47.9)$ & $466(52.1)$ \\
\hline Mansonia sp. & $1,990(12.7)$ & $1,074(54.0)$ & $916(46.0)$ \\
\hline Culex sp. & $764(4.9)$ & $380(49.7)$ & $384(50.3)$ \\
\hline Aedes sp. & $19(0.1)$ & $13(68.4)$ & $6(31.6)$ \\
\hline Total & 15,632 & $8,643(55.3)$ & $6,989(44.7)$ \\
\hline
\end{tabular}


Table 2

Mean values of entomological malaria parameters

\begin{tabular}{|c|c|c|c|c|}
\hline & $\begin{array}{l}\text { Capture } \\
\text { location }\end{array}$ & $\begin{array}{l}\text { An gambiae } \\
\text { s.l. }\end{array}$ & $\begin{array}{l}\text { An funestus } \\
\text { s.l. }\end{array}$ & $\begin{array}{l}\text { Both species } \\
\text { combined }\end{array}$ \\
\hline \multirow{3}{*}{$\begin{array}{l}\mathrm{HBR} \\
(\mathrm{b} / \mathrm{p} / \mathrm{n}) \\
{[95 \% \mathrm{Cl}]}\end{array}$} & Indoor & $\begin{array}{l}21.2[10.6- \\
31.8]^{a}\end{array}$ & $5.8[3.8-7.8]^{\mathrm{a}}$ & $25.8[15.2-36.2]^{a}$ \\
\hline & Outdoor & $\begin{array}{l}18.4[7.8-29.0] \\
\mathrm{a}\end{array}$ & $2.8[0.8-4.8]^{b}$ & $20.9[10.4-31.4]^{b}$ \\
\hline & Total & 19.8 [9.4-30.2] & $4.3[2.6-6.1]$ & 23.2 [12.8-33.6] \\
\hline \multirow{3}{*}{$\begin{array}{l}\text { Parity } \\
\text { (\%) } \\
{[95 \% \mathrm{Cl}]}\end{array}$} & Indoor & $\begin{array}{l}95.0[92.7- \\
97.0]^{a}\end{array}$ & $\begin{array}{l}98.8[97.4- \\
99.7]^{a}\end{array}$ & $96.9[95.1-98.3]^{a}$ \\
\hline & Outdoor & $\begin{array}{l}94.3[91.6- \\
96.5]^{a}\end{array}$ & $\begin{array}{l}98.8[97.0- \\
99.7]^{a}\end{array}$ & $96.3[94.1-97.9]^{\mathrm{a}}$ \\
\hline & Total & $\begin{array}{l}94.7[92.3- \\
96.7]\end{array}$ & $\begin{array}{l}98.8 \text { [97.6- } \\
99.6]\end{array}$ & 96.6 [94.7-98.1] \\
\hline \multirow{3}{*}{$\begin{array}{l}\text { SIR } \\
(\%) \\
{[95 \% \mathrm{CI}]}\end{array}$} & Indoor & $1.6[0.8-2.9]^{a}$ & $3.5[2.0-5.5]^{\mathrm{a}}$ & $1.8[1.0-2.9]^{a}$ \\
\hline & Outdoor & $1.5[0.7-2.7]^{a}$ & $6.4[3.8-9.9]^{b}$ & $2.2[1.3-3.5]^{a}$ \\
\hline & Total & $1.6[0.8-2.7]$ & $4.7[2.9-6.6]$ & $2.0[1.2-3.0]$ \\
\hline \multirow{3}{*}{$\begin{array}{l}\text { EIR } \\
\text { (ib/p/n) } \\
{[95 \% \mathrm{Cl}]}\end{array}$} & Indoor & $\begin{array}{l}0.22[0.15- \\
0.38]^{a}\end{array}$ & $\begin{array}{l}0.26[0.07- \\
0.44]^{a}\end{array}$ & $0.47[0.27-0.66]^{a}$ \\
\hline & Outdoor & $\begin{array}{l}0.22[0.11- \\
0.33]^{a}\end{array}$ & $\begin{array}{l}0.25(0.06- \\
0.44]^{a}\end{array}$ & $0.40[0.21-0.59]^{a}$ \\
\hline & Total & $\begin{array}{l}0.24[0.15- \\
0.34]\end{array}$ & $\begin{array}{l}0.25[0.08- \\
0.42]\end{array}$ & $0.43[0.25-0.61]$ \\
\hline \multicolumn{5}{|c|}{ SIR Sporozoite infection Rate; EIR Entomological Infection Rate; $C /$ confidence interval } \\
\hline
\end{tabular}

\section{Parity Rate}

Parity rate was high for both species caught indoor and outdoor; it averaged 94-95\% for An. gambiae s.I. and $99 \%$ for An. funestus s.l., with no significant differences in the rates indoor and outdoor $(P>0.05)$ (Table 2 and Supplementary Materials).

Plasmodium sporozoite infection rate 
Overall, infection rate for An. funestus s.l. (1.55\%) was significantly higher (3-fold) than for An. gambiae s.l. $(4.66 \%)\left(X^{2}=17.91, P<0.0001\right)$. There was no significant difference between the proportion infected outdoor and indoor for An. gambiaes.I (1.64\% vs 1.46\%; OR=1.11[0.65-1.9]; P=0.676), but for $A n$. funestus s.l., more individuals were infected outdoor (6.4\%) than indoor (3.5\%) (OR=1.86 [1.07-3.23]; $\mathrm{P}=0.0249$ ) (Table 2 and Supplementary Materials).

The majority of An. gambiae s.l. infected with malaria parasites harboured P. falciparum (90.6\%), and afew had P. malariae (9.4\%) (Table 3). There was no P. ovale detected in any of the samples tested for $A n$. gambiae s.l. Almost all An. funestus analysed were infected with $P$. falciparum (97\%) and only one individual had $P$. ovale (3\%), with no An. funestus s.l. testing positive for $P$. malariae (Table 3).

Table 3

Sporozoite infection rate (SIR) and malaria parasites.

\begin{tabular}{|c|c|c|c|c|c|c|c|}
\hline \multirow[t]{2}{*}{ Species } & \multirow{2}{*}{$\begin{array}{l}\mathrm{N}_{1} \\
\text { collected }\end{array}$} & \multirow{2}{*}{$\begin{array}{l}\mathrm{N}_{2} \\
\text { tested }\end{array}$} & \multirow{2}{*}{$\begin{array}{l}\text { \%SIR } \\
{[95 \% \mathrm{CI}]}\end{array}$} & \multicolumn{4}{|c|}{ Malaria parasite species } \\
\hline & & & & $\mathbf{N}$ & $\begin{array}{l}\% P . \\
\text { falciparum } \\
\text { (n) }\end{array}$ & $\begin{array}{l}\% \mathrm{P} \\
\text { malariae(n) }\end{array}$ & $\begin{array}{l}\text { \% P. } \\
\text { ovale (n) }\end{array}$ \\
\hline $\begin{array}{l}\text { An. } \\
\text { gambiae } \\
\text { s.l. }\end{array}$ & 10,350 & 1,373 & $\begin{array}{l}1.55[0.80- \\
2.67]\end{array}$ & 63 & $90.6(59)$ & $9.4(4)$ & - \\
\hline $\begin{array}{l}\text { An. } \\
\text { funestus } \\
\text { s.l. }\end{array}$ & 1,615 & 722 & $\begin{array}{l}4.66[2.93- \\
6.59]\end{array}$ & 59 & $97.0(58)$ & - & $3.0(1)$ \\
\hline Overall & 11,965 & 2,095 & $\begin{array}{l}1.96[1.17- \\
3.02]\end{array}$ & 122 & $95.90(117)$ & $3.28(4)$ & $0.82(1)$ \\
\hline
\end{tabular}

\section{Entomological Inoculation Rate}

The nightly EIR for An. gambiae s.I. and An. funestus s.I. were similar $(0.24-0.25 \mathrm{ib} / \mathrm{p} / \mathrm{n})$ and there were no significant differences between outdoor and indoor EIR for both species (Table 2).

Frequencies of the Kdr $1014 \mathrm{~F}$ and Ace- $1^{\mathrm{R}}$ 119S alleles in An. gambiae s.I.

Out of 1,374 An. gambiae s.I. mosquitoes analyzed by PCR, 1350 were successfully identified to species ( $<2 \%$ failure rate). Both An. gambiae s.s. $(\mathrm{n}=190 ; 14.1 \%)$ and An. coluzzii $(\mathrm{n}=1160 ; 85.9 \%)$ were found within the $A n$. gambiae complex analysed. For both $K d r$ and $A c e-1^{R}$ genes, the allelic frequencies were higher in An. gambiae than in An. coluzzii (P<0.001) (Table 4). 
Table 4

Kdr L 1014F and ace- $1^{R}$ G119S mutation frequencies in Anopheles gambiae s.l. populations.

\begin{tabular}{|c|c|c|c|c|c|c|c|}
\hline \multirow[t]{2}{*}{ Mutation } & \multirow[t]{2}{*}{ Species } & \multicolumn{4}{|l|}{$\mathbf{N}$} & \multirow[t]{2}{*}{ Allelic frequency } & \multirow[t]{2}{*}{$\mathrm{p}(\mathrm{HW})$} \\
\hline & & & SS & RS & RR & & \\
\hline \multirow[t]{2}{*}{$K d r \angle 1014 F$} & An. coluzzii & 1145 & 43 & 233 & 869 & $0.861^{a}$ & 0.000 \\
\hline & An. gambiae & 187 & 1 & 9 & 177 & $0.971^{b}$ & 0.140 \\
\hline \multirow[t]{2}{*}{ ace-1 G119S } & An. coluzzii & 1142 & 949 & 148 & 45 & $0.104^{a}$ & 0.000 \\
\hline & An. gambiae & 185 & 121 & 55 & 9 & $0.197^{b}$ & 0.362 \\
\hline \multicolumn{8}{|c|}{$\begin{array}{l}\text { Nnumber of mosquitoes genotyped; SS: susceptible; } R S \text { heterozygote; } R R \text { resistant; } p(H W) \text { exact } \\
\text { Hardy-Weinberg test } P \text {-value for each mutation, allelic frequencies with different superscript letters } \\
\text { differ significantly between species (G-test, } P<0.05)\end{array}$} \\
\hline
\end{tabular}

\section{Discussion}

Here we have provided a descriptive analysis of the entomological indicators relevant to malaria transmission in central Cote d'Ivoire, prior to the start of a CRT evaluating a new malaria vector control intervention.

The human malaria vector species that we found in the study area at the time of sampling (November December 2016) were An. gambiae s.l. and An. funestus s.l., with An. gambiae s.l. being more abundant. The predominance of $A n$. gambiae s.l. could be explained by the presence of breeding sites favorable to An. gambiae s.l. (e.g. rice paddy fields, vegetable plots, marshes) throughout the study area[19-21]. This aligns with previous studies conducted in the same area, and elsewhere in Côte d'Ivoire, which reported the predominance of An gambiae s.l. among local malaria vectors [22, 23].

An. gambiae and An. coluzzii were the only members of An. gambiae s.l. identified in the study area. An. coluzzii found in high proportion (85.90\%) was consistent with previous findings in the area of Bouaké[21, 24, 25] but contrasts with other studies in the northern savannah of the country, whereAn. gambiae was more prevalent[22,26]. The difference observed is likely due to variations in mosquito larval habitats; An. coluzzii tends to exploit more permanent breeding sites, including those created by the type of irrigation for rice cultivation found in Bouaké and the surrounding area. Permanent availability of breeding sites, due to intensive and perennial agricultural practices could have led to the presence of $A n$. coluzzi[27].

We found that increases in biting activity for both species coincided with the time when many people would be going to bed, with a peak in biting around 02:00 for An. gambiae s.I. and 03:00 for An. funestus 
s.l.. This is similar to previous entomological studies conducted in same area around Bouaké[20] as well as the northern part of Cote d'Ivoire [22,28] and elsewhere in Africa[29-31]. These biting profiles highlight the utility of insecticide treated bednets as a personal protective measure against host-seeking malaria vectors. However, the fact that outdoor biting An. gambiae s.l. mosquitoes were found in similar proportion to indoor biting mosquitoes is a sign that people are at risk of malaria transmission when they are outside in the evenings. It further highlights the need for novel strategies or tools to target outdoor malaria transmission[32, 33].

Mean parity rates and sporozoite infection rates were high in both species, especially in An. funestus s.l., indicating a high prevalence of older female mosquitoes who had already gone through several cycles of blood-feeding. Despite lower overall numbers, the sporozoite index rate for An. funestus s.l. was higher than An. gambiae s.I., indicating that it is still an important malaria vector in the area. These results are consistent with findings from previous studies in northern Côte d'Ivoire [22, 28], and show a need to better characterize the biology of An. funestus s.I. in this area[34], as well as careful monitoring of the epidemiological significance of An. funestus in malaria transmission; since in the current study, lots of clusters didn't have any An. funestus s.l. but they could be driving transmission in some clusters.

The mean nightly EIR in our study was 0.43 infected bites per person per night between NovemberDecember 2016. By extrapolation, it could correspond to 157 infected bites per person per year. Metaanalysis from a pool of studies conducted in various epidemiological settings across Africa reported EIRs ranging 1 to 1000 infected bites per person per year and that an annual EIR of 150 per person per year was consistently associated with malaria prevalence averaging 75\%[29]. Similarity, in a baseline epidemiological study conducted at a similar time, in the same area, prevalence was reported to be $73.9 \%$ [11]. The area around Bouaké can therefore be considered as highly endemic for malaria. Moreover, EIR in the study area was equally high indoor and outdoor, possibly due to inconsistent LLIN use, despite universal coverage, or compromised LLIN efficacy due to intense insecticide resistance [8].

Consistent with recent studies carried out in the area of Bouake $[6,8,24,35]$, there was a high frequency of both $K d r$ and $A c e 1^{R}$ genes in An. gambiae and An. coluzzii, with a higher frequency for An. gambiae. Resistant individuals seem to have better adaptive response in An. gambiae than An. coluzzii as evidenced elsewhere in Côte d'Ivoire[7, 36] and other parts in sub-Saharan Africa[22, 37, 38].

Resolving the problem posed by outdoor transmission of malaria has become critical[39, 40] LLINs and IRS are effective strategies controlling malaria but unfortunately they can only operate indoor [41, 42]. Once again the high outdoor transmission of malaria in our study triggers the urgent search for innovative tools or strategies to overcome outdoor transmission of malaria.

\section{Conclusion}

Densities of An. gambiaes.I. and An. funestus s.I. were high in central Côte d'Ivoire prior to the start of a CRT evaluating a new method of malaria vector control. Densities of An. gambiae s.I. were higher than 
An. funestus s.l., however An. funestus s.I. had higher rates of infection with Plasmodium parasites (sporozoite index). Consequently, EIR for these two species were similarly high, indicating that both species are probably important malaria vectors in the study area. Moreover, EIR was high both indoors and outdoors, despite universal coverage of LLINs in the area, which reinforces the urgent need for novel tools or strategies to address outdoor malaria transmission.

\section{Abbreviations}

WHO

World Health Organization

LLINs

Long Lasting Insecticidal Nets

IRS

Indoor Residual Spraying. L1014F Kdr.West knockdown resistance

Ace $-7^{R}$

Acetylcholinesterase-1 resistance

VCPEC

Vector Control Evaluation Centre

IPR

Institut Pierre Richet

Ace $-7^{R} \mathrm{G} 119 \mathrm{~S}$

G119S mutation in Ace- $7^{R}$

OR

odds ratio

$\mathrm{R}$

Resistant

$\mathrm{S}$

Susceptible

\section{Declarations}

\section{Acknowledgements}

We would like to thank the technical staff at the Institut Pierre Richet, Bouaké, Côte d'Ivoire for their valued support during mosquito collection surveys and laboratory analysis. The authors are very grateful to colleagues from various disciplines from Côte d'Ivoire, especially from the Unité de Recherche et de Pédagogie de Génétique, UFR Biosciences, Université Félix Houphouët-Boigny, Abidjan, for their useful contribution. We also thank the volunteer mosquito collectors in villages for their participation towards the study.

\section{Authors' contributions}


RZW, AAK and RN designed the study. RZW, LAT, YN, IZT, WAO and AAPL conducted the field and laboratory. RZW and AD analysed the data. RZW wrote the manuscript. AAK, AAPL, ONA, EDS, JC TBM and RN supervised the study and revised the manuscript. All authors reviewed and approved the final manuscript.

\section{Funding}

This study is supported by a grant to the Pennsylvania State University from the Bill \& Melinda Gates Foundation (OPP1131603), for evaluating the impact of an intervention composed of household screening plus a novel insecticide delivery system called In2Care EaveTubes.

\section{Availability of data and materials}

The datasets supporting the conclusions of this manuscript are included within the manuscript and its additional files, and are available from the corresponding author on reasonable request.

\section{Ethics approval and consent to participate}

Ethical clearance and consent information are included within the manuscript.

\section{Consent for publication}

Not applicable

\section{Competing interests}

The authors declare that they have no competing interests.

\section{Author details}

${ }^{1}$ Université Félix Houphouët-Boigny, UFR Biosciences, Unité de Recherche et de Pédagogie de Génétique, Abidjan, Côte d'Ivoire. ${ }^{2}$ Vector Control Product Evaluation Centre, Institut Pierre Richet (VCPEC-IPR), Bouaké, Côte d'Ivoire. ${ }^{3}$ Institut Pierre Richet (IPR) / Institut National de santé Publique (INSP), Bouaké, Côte d'Ivoire. ${ }^{4}$ Washington DC Department of Health, USA, ${ }^{5}$ Department of Entomology, Center for Infectious Disease Dynamics, The Pennsylvania State University; University Park, PA, USA. . ${ }^{6}$ Department of Vector Biology, Liverpool School of Tropical Medicine, Liverpool L3 5QA, UK, ${ }^{7}$ Department of Disease Control, London School of Hygiene and Tropical Medicine, London, UK., ${ }^{8}$ Université Alassane Ouattara, Bouaké, Côte d'Ivoire. ${ }^{9}$ Innovative Vector Control Consortium, IVCC, Liverpool, UK, ${ }^{10}$ London School of Hygiene and Tropical Medicine; International Statistics and Epidemiology Group, Department of Infectious Disease Epidemiology ${ }^{11}$ York Environmental Sustainability Institute, University of new York, USA.

\section{References}


1. Bhatt S, Weiss DJ, Mappin B, Dalrymple U, Cameron E, Bisanzio D, et al. Coverage and system efficiencies of insecticide-treated nets in Africa from 2000 to 2017. eLife. 2015; 4:e09672

2. Ranson H, N'Guessan R, Lines J, Moiroux N, Nkuni Z, Corbel V. Pyrethroid resistance in African anopheline mosquitoes: what are the implications for malaria control? Trends Parasitol. 2011; 27:91-8.

3. World malaria report 2020: 20 years of global progress and challenges.: 299.

4. Riveron JM, Irving H, Ndula M, Barnes KG, Ibrahim SS, Paine MJI, et al. Directionally selected cytochrome P450 alleles are driving the spread of pyrethroid resistance in the major malaria vector Anopheles funestus. Proc Natl Acad Sci USA. 2013; 110:252-7.

5. Mulamba C, Riveron JM, Ibrahim SS, Irving H, Barnes KG, Mukwaya LG, et al. Widespread Pyrethroid and DDT Resistance in the Major Malaria Vector Anopheles funestus in East Africa Is Driven by Metabolic Resistance Mechanisms. PLoS ONE. 2014; 9:e110058.

6. Koffi AA, Ahoua Alou LP, Adja MA, Chandre F, Pennetier C. Insecticide resistance status of Anopheles gambiae s.s population from M'Bé: a WHOPES-labelled experimental hut station, 10 years after the political crisis in Côte d'Ivoire. Malaria J. 2013;12:151.

7. Kouassi BL, Edi C, Tia E, Konan LY, Akré MA, Koffi AA, et al. Susceptibility of Anopheles gambiae from Côte d'Ivoire to insecticides used on insecticide-treated nets: evaluating the additional entomological impact of piperonyl butoxide and chlorfenapyr. Malar J. 2020;19:454.

8. Oumbouke WA, Pignatelli P, Barreaux AMG, Tia IZ, Koffi AA, Ahoua Alou LP, et al. Fine scale spatial investigation of multiple insecticide resistance and underlying target-site and metabolic mechanisms in Anopheles gambiae in central Côte d'Ivoire. Sci Rep. 2020; 10: 15066.

9. Knols BGJ, Farenhorst M, Andriessen R, Snetselaar J, Suer RA, Osinga AJ, et al. Eave tubes for malaria control in Africa: an introduction. Malaria J. 2016; 15:404.

10. Andriessen R, Snetselaar J, Suer RA, Osinga AJ, Deschietere J, Lyimo IN, et al. Electrostatic coating enhances bioavailability of insecticides and breaks pyrethroid resistance in mosquitoes. Proceedings of the National Academy of Sciences. 2015; 112:12081-6.

11. Sternberg ED, Cook J, Alou LPA, Assi SB, Koffi AA, Doudou DT, et al. Impact and cost-effectiveness of a lethal house lure against malaria transmission in central Côte d'Ivoire: a two-arm, clusterrandomised controlled trial. The Lancet. 2021; 397:805-15.

12. Sternberg ED, Cook J, Ahoua Alou LP, Aoura CJ, Assi SB, Doudou DT, et al. Evaluating the impact of screening plus eave tubes on malaria transmission compared to current best practice in central Côte d'Ivoire: a two armed cluster randomized controlled trial. BMC Public Health. 2018; 18: 894.

13. Gillies MT, Meillon B de. The Anophelinae of Africa south of the Sahara. Suppl: Afrotropical region. Johannesburg; 1987; 55.

14. Detinova TS. Age-grouping methods in diptera of medical importance: 1962; 213.

15. Mangold KA, Manson RU, Koay ESC, Stephens L, Regner M, Thomson RB, et al. Real-Time PCR for Detection and Identification of Plasmodium spp. J Clin Microbiol. 2005; 43:2435-40. 
16. Favia G, Lanfrancotti A, Spanos L, Sidén-Kiamos I, Louis C. Molecular characterization of ribosomal DNA polymorphisms discriminating among chromosomal forms of Anopheles gambiaes.s.: An. gambiae s.s. rDNA polymorphisms. Insect Mol Biol. 2001; 10:19-23.

17. Bass C, Nikou D, Donnelly MJ, Williamson MS, Ranson H, Ball A, et al. Detection of knockdown resistance (kdr) mutations in Anopheles gambiae: a comparison of two new high-throughput assays with existing methods. Malar J. 2007; 6:111.

18. Bass C, Nikou D, Vontas J, Williamson MS, Field LM. Development of high-throughput real-time PCR assays for the identification of insensitive acetylcholinesterase (ace-1R) in Anopheles gambiae. Pestic Biochem Physio. 2010; 96:80-5.

19. Dossou-yovo J, Doannio J, Rivière F, Duval J. Rice cultivation and malaria transmission in Bouaké city (Côte d'Ivoire). Acta Trop. 1994; 57:91-4.

20. Dossou-Yovo J, Doannio JMC, Diarrassouba S, Chauvancy G. The impact of rice fields on the transmission of malaria in Bouake, Cote d'Ivoire. Bulletin de la société de pathologie exotique. 1998;91:327-33.

21. Zoh DD, Yapi A, Adja MA, Guindo-Coulibaly N, Kpan DMS, Sagna AB, et al. Role of Anopheles gambiae s.s. and Anopheles coluzzii (Diptera: Culicidae) in Human Malaria Transmission in Rural Areas of Bouaké, in Côte d'Ivoire. Hamer G, editor. J Med Entomol. 2020; 57:1254-61.

22. Zogo B, Soma DD, Tchiekoi BN, Somé A, Ahoua Alou LP, Koffi AA, et al. Anopheles bionomics, insecticide resistance mechanisms, and malaria transmission in the Korhogo area, northern Côte d'Ivoire: a pre-intervention study. Parasite. 2019; 26:40.

23. Yokoly FN, Zahouli JBZ, Small G, Ouattara AF, Opoku M, de Souza DK, et al. Assessing Anopheles vector species diversity and transmission of malaria in four health districts along the borders of Côte d'Ivoire. Malar J. 2021;20:409.

24. Camara S, Koffi AA, Ahoua Alou LP, Koffi K, Kabran J-PK, Koné A, et al. Mapping insecticide resistance in Anopheles gambiae (s.I.) from Côte d'Ivoire. Parasit Vectors. 2018;11:19.

25. Koffi AA, Ahoua Alou LP, Djenontin A, Kabran J-PK, Dosso Y, Kone A, et al. Efficacy of Olyset ${ }^{\circledR}$ Duo, a permethrin and pyriproxyfen mixture net against wild pyrethroid-resistant Anopheles gambiae s.s. from Côte d'Ivoire: an experimental hut trial. Parasite. 2015;22:28.

26. Zogo B, Koffi AA, Alou LPA, Fournet F, Dahounto A, Dabiré RK, et al. Identification and characterization of Anopheles spp. breeding habitats in the Korhogo area in northern Côte d'Ivoire: a study prior to a Bti-based larviciding intervention. Parasites Vectors. 2019; 12:146.

27. Gimonneau G, Pombi M, Choisy M, Morand S, Dabiré RK, Simard F. Larval habitat segregation between the molecular forms of the mosquito Anopheles gambiae in a rice field area of Burkina Faso, West Africa. Med Vet Entomol. 2012; 26:9-17.

28. Adja AM, N'Goran KE, Kengne P, Koudou GB, Toure M, Koffi AA, et al. Vectorial transmission of malaria in shrubby Savannah area at Ganse, Ivory Coast. Med. Trop. 2006; 66:449-55.

29. Killeen GF, Githure JI, Beier JC. Short report: entomologic inoculation rates and Plasmodium falciparum malaria prevalence in Africa. Am J Trop Med Hyg. 1999; 61:109-13. 
30. Kilama M, Smith DL, Hutchinson R, Kigozi R, Yeka A, Lavoy G, et al. Estimating the annual entomological inoculation rate for Plasmodium falciparum transmitted by Anopheles gambiae s.l. using three sampling methods in three sites in Uganda. Malaria J. 2014; 13: 111.

31. Conn JE, Norris DE, Donnelly MJ, Beebe NW, Burkot TR, Coulibaly MB, et al. Entomological Monitoring and Evaluation: Diverse Transmission Settings of ICEMR Projects Will Require Local and Regional Malaria Elimination Strategies. Am J Trop Med Hyg. 2015; 93:28-41.

32. Russell, T.L., Govella, N.J., Azizi, S. et al. Increased proportions of outdoor feeding among residual malaria vector populations following increased use of insecticide-treated nets in rural Tanzania. Malar J. 2011; 10: 80.

33. Musiime, A.K., Smith, D.L., Kilama, M. et al. Impact of vector control interventions on malaria transmission intensity, outdoor vector biting rates and Anopheles mosquito species

34. Byrne I, Chan K, Manrique E, Lines J, Wolie RZ, Trujillano F, et al. Technical Workflow Development for Integrating Drone Surveys and Entomological Sampling to Characterise Aquatic Larval Habitats of Anopheles funestus in Agricultural Landscapes in Côte d'Ivoire. J. Environ. Public Health. 2021; 2021:1-14.

35. Wolie RZ, Koffi AA, Ahoua Alou LP, Sternberg ED, N'Nan-Alla O, Dahounto A, et al. Evaluation of the interaction between insecticide resistance-associated genes and malaria transmission in Anopheles gambiae sensu lato in central Côte d'Ivoire. Parasit Vectors. 2021; 14:581.

36. Alou LPA, Koffi AA, Adja MA, Assi SB, Kouassi PK, N'Guessan R. Status of pyrethroid resistance in Anopheles gambiaes. s. M form prior to the scaling up of Long Lasting Insecticidal Nets (LLINs) in Adzope, Eastern Cote d'Ivoire. Parasit Vectors. 2012;5.

37. Koukpo CZ, Fassinou AJYH, Ossè RA, Agossa FR, Sovi A, Sewadé WT, et al. The current distribution and characterization of the $L 1014 \mathrm{~F}$ resistance allele of the kdr gene in three malaria vectors (Anopheles gambiae, Anopheles coluzzii, Anopheles arabiensis) in Benin (West Africa) Malaria J. 2019; 18:175.

38. Soma DD, Zogo BM, Somé A, Tchiekoi BN, Hien DFS, Pooda HS, Coulibaly S, Gnambani JE, Ouari A, Mouline K, Dahounto A, Ouédraogo GA, Fournet F, Koffi AA, Pennetier C, Moiroux N, Dabiré RK. Anopheles bionomics, insecticide resistance and malaria transmission in southwest Burkina Faso: $A$ pre-intervention study. PLoS One. 2020; 3;15(8):e0236920.

39. Moshi IR, Manderson L, Ngowo HS, Mlacha YP, Okumu FO, Mnyone LL. Outdoor malaria transmission risks and social life: a qualitative study in South-Eastern Tanzania. Malaria J. 2018; 17, 397.

40. Russell TL, Govella NJ, Azizi S, Drakeley CJ, Kachur SP, Killeen GF. Increased proportions of outdoor feeding among residual malaria vector populations following increased use of insecticide-treated nets in rural Tanzania. Malar J. 2011;10:80.

41. Dossou-Yovo J, Guillet P, Rogier C, Chandre F, Carnevale P, Assi S-B, et al. Protective efficacy of lambda-cyhalothrin treated nets in Anopheles gambiae pyrethroid resistance areas of Côte d'Ivoire. Am J Trop Med Hyg. 2005; 73:859-64. 
42. Bhatt S, Weiss DJ, Cameron E, Bisanzio D, Mappin B, Dalrymple U, et al. The effect of malaria control on Plasmodium falciparum in Africa between 2000 and 2015. Nature. 2015;526:207-11.

\section{Figures}

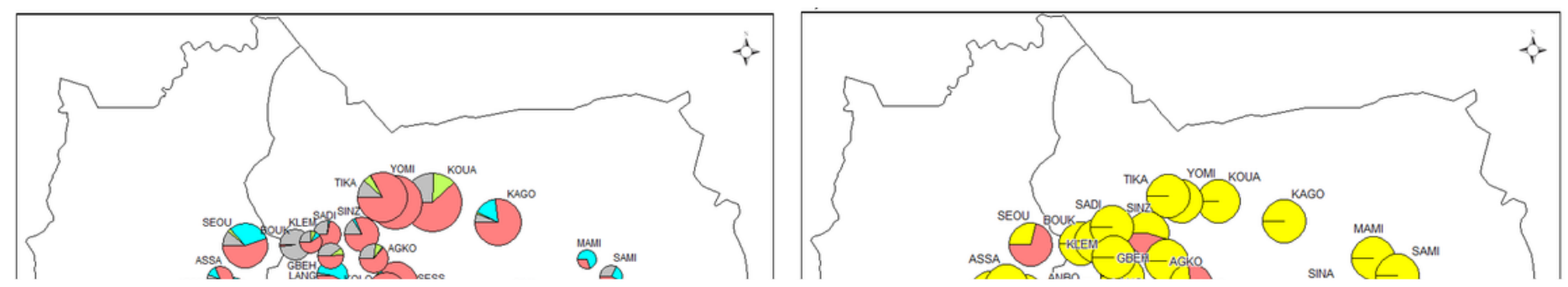

\section{Figure 1}

Map of mosquito densities and composition in the 40 village-clusters of the study area. A) Overall mosquito density; B) An. gambiae s.l. species complex distribution in the forty (40) villages

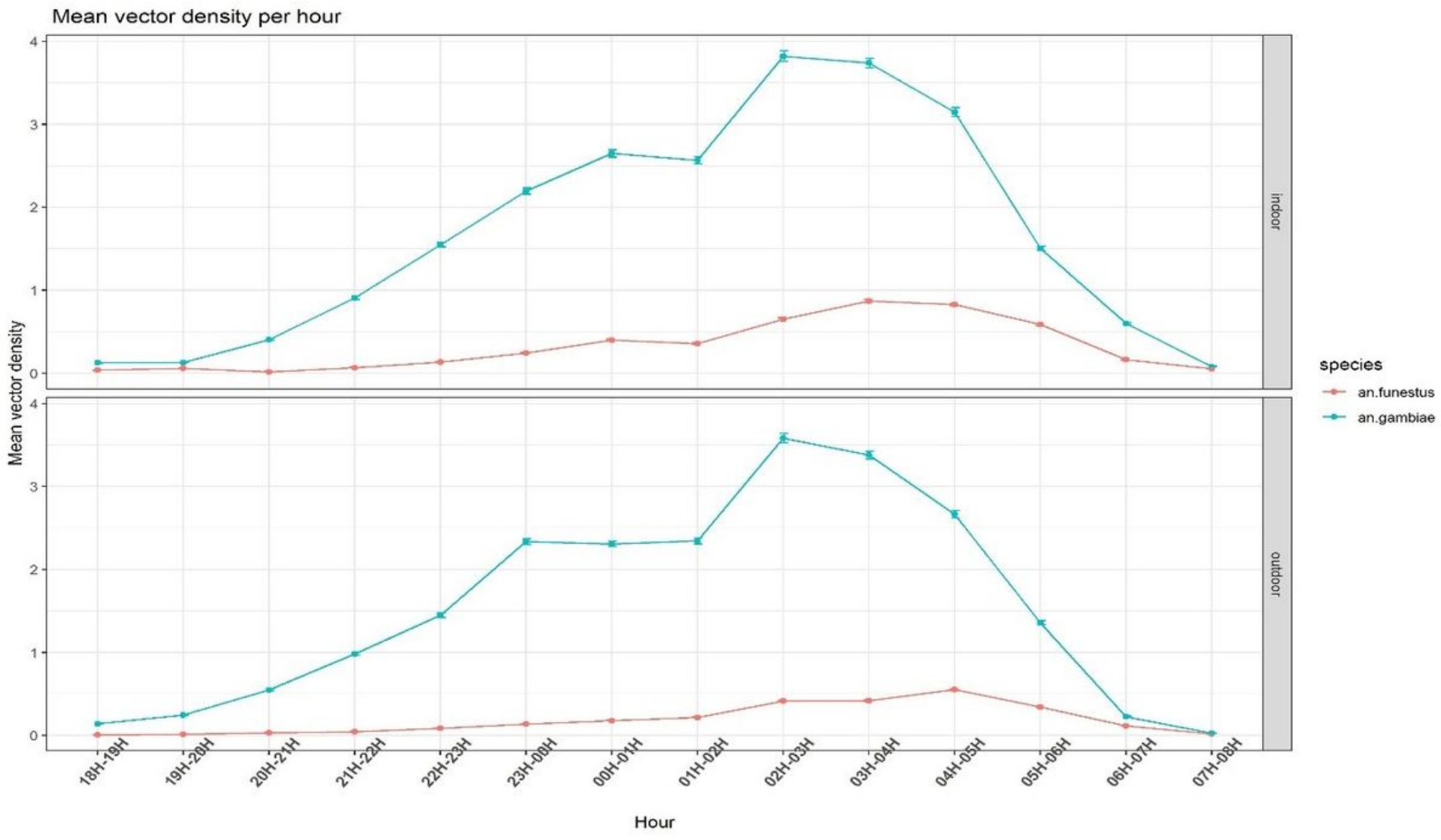

Page $17 / 18$ 
Figure 2

Hourly outdoor and indoor biting profiles of An. gambiaes.l. and An. funestus across all the study villages. Points show mean and bars indicate hourly change in number of mosquito bites

\section{Supplementary Files}

This is a list of supplementary files associated with this preprint. Click to download.

- SupplementaryMaterialsRosineZ.Wolie.docx 